\title{
Juego Problemático: La Importancia de Dimensionar con Precisión para
}

\section{la Toma de Decisiones}

\section{Problematic Gambling: The Importance of Accuracy in Policy Making}

* Juan Lacarra Albizu

Secretario General de la Asociación Española de Empresarios de Salones de Juego y Recreativos (ANESAR). España / Spain

jlacarra@anesar.com

Agradezco la invitación de la Revista Española de Sociología a participar en el debate sobre el trabajo "La transformación del juego problemático en España". Mi aportación tiene que ser profesional, en la medida en que esta es una investigación sociológica aplicada, que afecta a un tema central para la industria del juego y su imagen. Con estudios científicos y profesionales sobre el juego problemático, el sector empresarial está mucho más amparado y preparado para defender esta actividad como un entretenimiento del que se deriva una industria que genera más de 40000 empleos y varios cientos de empresas, algunas multinacionales. Sería positivo que a partir de los estudios que aquí se sintetizan los medios y la sociedad española llegara a la conclusión de que "Los españoles, cuando juegan, Io hacen de forma responsable y no problemática". Esa es una visión del pasado.

En todos los órdenes de la vida hay un porcentaje de individuos que parece incapaz de medir y controlar sus impulsos. En el caso del juego, es el $0,3 \%$, y no por ser pocos dejan de requerir atención ante un problema personal perjudicial para ellos y su entorno. Desde el punto de vista práctico, la evidencia que resulta de este artículo es que no cabe magnificar la dimensión de este problema ni ocultar la positiva evolución de la sociedad española en el último cuarto de siglo.

Una llamativa característica del sector empresarial del juego es su actitud ante las exageraciones "informativas" sobre el juego problemático, sin base alguna. Las asume como una penitencia autoimpuesta que no sabe 0 , lo que es más extraño, no quiere contrarrestar. Esto se debe a que no ha contado hasta ahora con los datos con rigor científico imprescindibles para contextualizar este supuesto problema social. Por tanto, esta investigación tiene una gran importancia para las empresas del juego que muchas veces han adoptado la actitud, si se permite el símil cinematográfico, de sospechosos, es decir, invocar el derecho a no declarar porque "cualquier cosa que diga puede ser utilizada en su contra".

Incluso en estos días, se leen titulares en prensa como "Más de 30000 onubenses padecen alguna ludopatía" (Huelva información) y "datos" que apuntan que en Andalucía hay 200000 ludópatas, o se afirma que en Aragón "Es un problema serio, muy grave, y se convertirá en pandemia porque hay muchos jóvenes afectados. Está descontrolado".

*Autor para correspondencia / Corresponding author: Juan Lacarra Albizu. ANESAR, c/. José Ortega y Gasset, 25-bajo. 28006 Madrid.

Sugerencia de cita / Suggested citation: Lacarra Albizu, J. (2017). Juego Problemático: La Importancia de Dimensionar con Precisión para la Toma de Decisiones. Revista Española de Sociología, 26 (2), 253-255. 
Son filtraciones que normalmente provienen de asociaciones de jugadores en rehabilitación que deben pensar que su labor mejora cuando exageran las cifras y sin que las mismas vengan soportadas, que sepamos, por ningún análisis ni estudio.

Dimensionar correctamente este problema es absolutamente necesario para saber de qué estamos hablando y si de verdad estamos ante un problema "al borde de la pandemia" o una "enfermedad" cuantitativamente limitada. Y no sólo eso, también necesitamos saber y conocer cuál es el problema y dónde reside, en qué juegos y a qué perfil de la población afecta. Ello nos permitirá adoptar medidas proporcionadas pero también asumir y repartir, en su caso, la responsabilidad que nos toque a cada uno de los que formamos parte de este sector — público, privado y semipúblicos-.

Como punto de partida e inicio de toda actuación encaminada a estudiar acciones de responsabilidad social en el juego, necesitamos conocer los datos. Es lo mínimo imprescindible para emprender, tanto el sector como las instituciones, un camino u otro. La síntesis de los 20 estudios realizados en España en los últimos 25 años y su comparación con los principales países desarrollados son una aportación relevante para el sector del juego.

Se debe tener en cuenta que no todos los juegos son iguales, ni tampoco sus gestores. El Estado es el mayor operador a través de SELAE (Sociedad Estatal de Loterías y Apuestas del Estado) y la ONCE tiene varias loterías, con amplia publicidad en ambos casos. Sin embargo, por alguna corrección política, nadie parece dispuesto a contemplar el juego gestionado por el Estado como posible fuente de comportamientos no deseables. La publicidad realizada 0 el carácter social y benéfico de algunos de estos juegos parecen eximirlos de responsabilidad alguna, otorgando una especie de bendición que justifica el no establecer unas medidas de control que sin embargo se exigen al sector privado: "Hay que jugar a la primitiva porque no tenemos sueños baratos", es el lema de una campaña reciente. Seguramente sería una sorpresa para la opinión pública saber que el dinero que se reparte en premios en estas loterías públicas o semipúblicas es sensiblemente menor que el que se distribuye en los casinos, bingos, salones de juego y apuestas deportivas.
En lo que se refiere al sector privado del juego las medidas de control son exhaustivas. La publicidad está restringida, es impensable una campaña con el eslogan "Hay que jugar a las máquinas, porque no tenemos sueños baratos". Hay múltiples medidas de control de acceso a las salas, todas ellas tendentes a evitar conductas de juego problemático, que las empresas gestionan con eficacia. El sector siempre las ha interiorizado, comprendido y aplicado de manera responsable, como una herramienta a disposición de los individuos cuyo comportamiento ante el juego no es el deseable. Al contrario de las visiones distorsionadas, a las empresas privadas del juego no desean la presencia en sus establecimientos de jugadores problemáticos, puesto que esta conducta suele estar acompañada de otros de comportamientos que afectan a nuestra imagen y que en muchas ocasiones incomodan a otros clientes que deciden pasar su tiempo libre en nuestros establecimientos. Es sencillo, ningún comercio quiere clientes "pesados" con otros clientes. Sirva esto para despejar algunas ideas preconcebidas. Una de las aportaciones de este artículo es su referencia al juego problemático como parte de un síndrome que suele incluir varias patologías.

Sentada la base de que en el juego presencial privado existen sistemas destinados a controlar el acceso al juego de menores y "autoprohibidos", deberíamos preguntarnos por qué en otros juegos públicos, como los gestionados por SELAE no existen estos controles, ni en lo que se refiere a los clientes ni tampoco en publicidad. También cabría preguntarse por la eficacia de estos controles cuando, por ejemplo, el juego se realiza a través del canal online. Los controles existen y son rigurosos en este apartado pues todo jugador online ha de registrarse, pero deviene en imposible saber si la persona que realmente juega online desde su casa coincide con el DNI registrado en el sistema. El control "presencial" que se hace en los establecimientos físicos de juego es mucho más eficaz en este sentido.

Es paradójico que los juegos en los que hay más y mejores medidas de protección al cliente, como las máquinas, aparezcan ante la opinión pública como los que mayor peligro parecen encerrar.

Los resultados que por primera vez publica este estudio muestran que las medidas establecidas funcionan, y por eso hay felicitar a las Administra- 
ciones y a las empresas del juego que responsablemente cumplen con sus obligaciones.

La evidencia científica aquí sintetizada muestra que los ciudadanos son responsables de que no exista ninguna "pandemia", y que el juego es una opción de ocio normal.

\section{NOTA BIOGRÁFICA}

Juan Lacarra Albizu es abogado. Secretario General Técnico de la Asociación Española de Empresarios de Salones de Juego y Recreativos (ANESAR). 
